\title{
Erratum to: Transport effects of e-commerce: what can be learned after years of research?
}

\author{
Orit Rotem-Mindali $\cdot$ Jesse W. J. Weltevreden
}

Published online: 1 May 2013

(C) Springer Science+Business Media New York 2013

\section{Erratum to: Transportation DOI 10.1007/s11116-013-9457-6}

Unfortunately, the Acknowledgement section was not included in the originally published article.

Acknowledgments The authors express their gratitude to Patricia L. Mokhtarian for her helpful suggestions, contribution and comments on the earlier draft of the manuscript. Any remaining errors of fact or interpretation are the authors own responsibility.

The online version of the original article can be found under doi:10.1007/s11116-013-9457-6.

O. Rotem-Mindali ( $₫)$

Department of Geography and Environment, Bar Ilan University, 52900 Ramat Gan, Israel e-mail: orit.rotem@biu.ac.il

J. W. J. Weltevreden

Hogeschool van Amsterdam, University of Applied Science, P.O. Box 1025, 1000 BA Amsterdam, The Netherlands

e-mail: jweltevreden@gmail.com 